\title{
O Choro no interior de São Paulo: a evolução e importância do Choro Avareense (1951-1990)
}

\author{
Caio Vinícius Zévola Orru \\ Faculdades Integradas Regionais de Avaré \\ caiovzorru@gmail.com
}

\begin{abstract}
Resumo: Este trabalho tem por objetivo buscar as origens do Choro em Avaré, cidade localizada no interior do Estado de São Paulo. Situamos nosso recorte entre os anos de 1951-1990, pois compreendemos esse período como basilar para o desenvolvimento do Choro Avareense. Iniciaremos com uma breve contextualização do Choro em São Paulo, para chegarmos até o nosso recorte, o surgimento e a evolução da cultura "chorística" em Avaré. Assim, poderemos compreender como o Choro se interioriza; sendo isso, um reflexo da pressão das bases econômicas sobre a superestrutura. $\mathrm{O}$ Choro produzido em Avaré e seus músicos têm grande importância e relevância para a evolução do gênero musical, a exemplo do citadino Jamil Caram, que foi um chorão de estirpe nacional. Desta maneira, perscrutaremos desde o primeiro chorão da cidade até a mais concreta realização do Choro avareense, o Clube do Choro de Avaré.
\end{abstract}

Palavras-chave: Choro, Cultura, Avaré.

\section{The Choro inside São Paulo: the evolution and importance of Choro Avareense (1951- 1990)}

Abstract: This work aims to search for the origins of Choro in Avaré, a city located in the interior of the State of São Paulo. We situate our cut between the years 1951-1990, as we understand this period as the basis for the development of Choro Avareense. We will start with a brief contextualization of Choro in São Paulo, to arrive at our cut, the emergence and evolution of the "choristic" culture in Avaré. Thus, we will be able to understand how Choro is internalized; this being, a reflection of the pressure of the economic bases on the superstructure. The Choro produced in Avaré and its musicians has great importance and relevance for the evolution of the musical genre, like the city Jamil Caram, who was a chorão of national strain. In this way, we will scrutinize from the first chorão in the city to the most concrete realization of Choro Avareense, the Avaré Choro Club.

Keywords: Choro, Culture, Avaré.

\section{Introdução}

Choro, o primeiro gênero musical brasileiro tipicamente urbano, "[...] instrumentistas do Rio de Janeiro, [...], lá por 1870, começaram a fazer música brasileira - brasilidade que estava menos na origem do que na execução" (VASCONCELOS, 1984, p. 18). Quando falamos no gênero, logo pensamos em Pixinguinha (1897-1973), Jacob do Bandolim (1918-1969), Waldir Azevedo (1923-1980), Chiquinha Gonzaga (1847-1935) e Ernesto Nazareth (1863-1934). Músicas amplamente conhecidas e de presença constante na história do brasileiro, como "Ticotico no fubá" e "Carinhoso", são exemplos de um choro popular, formado por uma miscelânea de gêneros musicais que acabaram por formatar um só gênero no início do século XX. O Lundu dos escravos negros, a polca, o maxixe, modinhas, fados, fofas, mazurcas, tango brasileiro, entre outros, eram os estilos musicais em voga no Brasil colônia, “[...] o choro, inicialmente 
não propriamente um gênero, mas um conjunto instrumental e logo um jeito brasileiro de se tocar a música europeia da época" (VASCONCELOS, 1991, p. 34), também passou a disputar seu espaço no imaginário musical de nosso país.

Em sua gênese, advém das músicas feitas pelos negros escravizados da Bahia e do Rio de Janeiro, a chamada música de barbeiros, “[...] um tipo de música instrumental que por sua origem, espírito e função já se poderia chamar de popular" (TINHORÃO, 2010 p.163). Passando por um longo processo social de formação, sendo aderido pelas classes trabalhadoras que se formavam no Rio de Janeiro no final do Império, para então se consolidar como gênero musical com Pixinguinha no início do século XX, “[...] evoluiu de música dançante para música virtuosística, feita para ser ouvida e apreciada" (SEVERIANO, 2017, p. 34). Ora, mas o que isso tem de haver com Avaré e o Choro produzido na cidade?

A cultura sempre esteve ligada à vida avareense, músicos e artistas de grande estirpe passaram, foram formados e revelados em Avaré, como a citadina e grande pintora Djanira. A cidade é conhecida e respeitada nacionalmente por sua histórica feira de música popular, a FAMPOP. Em relação ao Choro, Avaré entra na rota da cultura "chorística" nacional e paulista pelo grande músico e chorão Jamil Caram, que trouxe estimados chorões para a cidade, a exemplo de Izaías do Bandolim e Altamiro Carrilho, e pelo também popular Festival de Choro de Avaré, que contou, em uma de suas edições, com a presença de Déo Rian, o colírio dos olhos de Jacob do Bandolim. O Choro avareense produziu grandes músicos da nova geração, como o percussionista Rafael Toledo e o violonista João Camarero -, que hoje ocupa a cadeira de Dino Sete cordas em um dos conjuntos mais renomados da história do Choro, o "Época de Ouro", criado por Jacob do Bandolim.

Partindo de uma breve contextualização do Choro no estado de São Paulo, buscaremos compreender sua formação na cidade de Avaré, situada no interior do estado, para, então, entrarmos em nosso recorte, de 1951-1990. Selecionamos esse período porque o Choro avareense toma forma, em um primeiro momento, na Rádio local, em 1951, sobretudo por esforço de Luiz de Paschoal, consolidando-se, nos anos de 1990, com o então embrionário Clube do Choro de Avaré.

Por conseguinte, dissertaremos sobre a cultura e a cidade de Avaré para estabelecermos a formação do Choro, e apresentaremos o embrião do gênero na cidade; falaremos sobre a profissionalização do Choro avareense, que carrega o nome de dois chorões citadinos, Antônio 
Teixeira de Abreu e Jamil Caram, para chegarmos à materialização dos feitos dos originários chorões, O Clube do Choro de Avaré.

Partindo das contribuições da escola britânica de crítica cultural materialista, selecionamos o trabalho de Raymond Williams como referência para a crítica cultural alinhada com a realidade social. Compreendemos que o materialismo cultural se diferencia dos demais estudos culturais isolados porque associa as análises culturais à crítica dos fatores determinantes na sociedade, sendo eles econômicos, políticos e sociais. Utilizaremos também a concepção marxista de luta de classes, considerada necessária para a incursão que se faz neste artigo.

Investigaremos a consolidação do Choro no estado de São Paulo, para, assim, buscarmos as origens do gênero na cidade de Avaré/SP. Apresentaremos seus principais chorões e seus empreendimentos, amparando-nos nos conceitos de base e superestrutura propostos por Williams e em sua concepção de hegemonia, que "constitui então, em sentido de realidade para a maioria das pessoas em uma sociedade, um sentido absoluto por se tratar de uma realidade vivida" (WILLIAMS, 2011, p. 53). Logo, compreendemos que as determinações políticas, sociais e econômicas que alicerçaram a formação do Choro sucederam a construção do Choro avareense, reverberando em sua evolução. Entendemos, pois, que a cultura local não pode ser vista como isolada da sociedade, "uma vez que a produção cultural é por si só vista como social e material... já não é mais baseada na experiência, mas no caráter comum dos respectivos processos de produção" (WILLIAMS, 1979, p. 139).

A história das ideias não pode ser separada da economia e da filosofia, o historiador social que negligenciar um dos dois, não chegará ao seu ponto. $\mathrm{O}$ passado influencia o futuro, mas não é passivo de imobilidade social, depende de uma determinada circunstância, de uma determinada sociedade, aponta o historiador Eric Hobsbawm (2013), reforçando as impressões de Williams sobre base e superestrutura.

\footnotetext{
Então, devemos dizer que quando falamos de "base", estamos falando de um processo, e não de um estado. E não podemos atribuir a esse processo algumas propriedades fixas a serem posteriormente traduzidas aos processos variáveis da superestrutura" (WILLIAMS, 2011, p. 47).
}

A pesquisa bibliográfica foi escolhida para fazermos uma incursão em nosso objeto de estudo, tanto para compreendermos os grandes autores da música popular brasileira, quanto os processos do materialismo cultural; para um diálogo e debate teórico mais amplo, utilizamos dissertações, artigos de revistas e jornais, e trabalhos de conclusão de curso. 
Para compor esta pesquisa, buscamos fontes sobre a história do Choro em Avaré, realizamos entrevistas e selecionamos alguns documentos pessoais das personagens aqui citadas, bem como o trabalho de conclusão de curso, Clube do choro Jamil Caram, de Eduardo Teixeira Neto (2014). Levantamos uma bibliografia sobre a história de Avaré, destacamos os livros Um pouco da história do Avaré, outrora Rio Novo (1996), de Jango Pires; Uma Divertida Máquina do Tempo em Avaré (2008), de Flora Bocci; e Avaré em memória viva (2011/2012), de Gesiel Júnior.

\title{
O Choro em São Paulo
}

Podemos citar o nome de Aníbal Augusto Sardinha, o Garoto, que revolucionou a brasilidade nas músicas. Garoto nasceu em 28 de junho de 1915, na Vila Economizadora, uma área operária fundada em 1907, no bairro da Luz, junto ao rio Tamanduateí, e atual linha férrea da CPTM, vizinho do Brás e do Pari (REVISTA DO CHORO, 2015), em São Paulo. Ao lado de Carmem Miranda, torna-se reconhecido internacionalmente por seu solo de violão tenor na música "South American Way". Foi prestigiado também pelo cineasta Woody Allen - que, aliás, é clarinetista, e incluiu o solo de Garoto em seu filme Rádio Day. No Brasil, Chico Buarque e o poeta Vinícius de Moraes deram letra a sua composição "Gente Humilde". Ao lado de Chiquinho do Acordeon compõe seu maior sucesso, "São Paulo Quatrocentão" (DINIZ, 2003).

\begin{abstract}
Garoto disputava com Jacob do Bandolim o título de melhor instrumentista de quatro cordas. Garoto era mais inventivo, e Jacob, mais detalhista [...] com o tempo, a importância de Garoto foi se revelando por completo. Revolucionou o choro, criou a moderna escola de violão brasileiro, foi o verdadeiro precursor da bossa nova (inclusive dando aulas a Carlos Lyra, pouco antes de morrer) [...] Garoto foi o precursor de Jacob [...] A música popular brasileira do século tem algumas pessoas seminais. Garoto foi uma delas. Era uma espécie de Mozart, no talento e na fragilidade. Intrinsecamente musical, como todo gênio tinha a falta de prática para a vida. Não fez carreira nos Estados Unidos porque sua primeira mulher sofreu discriminações de cor (NASSIF, in: Folha de São Paulo, 28/3/1999).
\end{abstract}

São Paulo é, sem dúvida, um estado que respira, vive e dissemina o Choro; também por causa de um despretensioso chorão, que em sua cidadezinha do interior paulista, chamada Santa Rita do Passo Quatro, soou acordes em um pacato baile e fez nascer "Tico-Tico no Farelo", ou "Tico-Tico no Fubá", parte do imaginário e da memória afetiva dos brasileiros. Todo brasileiro, alguma vez na vida, já escutou Zequinha de Abreu. Com isso, a zombaria vinda dos cariocas se esvaiu, e "a qualidade e quantidade de nomes vindos de São Paulo fizeram desaparecer o descrédito [...] [de] muitas décadas" (CAZES, 2010, p. 91). 
Outros grandes nomes fizeram parte da rota "chorística" de São Paulo, como o grande Américo Jacobino (O Canhoto). "Solava como poucos, era de invejar a sua eletricidade nas cordas do seu mavioso violão" (PINTO, 2014 p.112). Bem como o violonista Armando Neves, cuja história é deveras interessante, pois foi de ofício jogador de futebol. Nascido em Campinas, defendeu os dois times da cidade, uma das maiores rivalidades do futebol brasileiro, Ponte Preta e Guaraní. Na capital paulista, chegou a jogar no Corinthians, transferiu-se então para a música, e foi figura importante e marcante no Choro paulistano (CAZES, 2010). Na década de 1970, o ilustre Izaías Bueno montou seu regional e reverberou o Choro nacional, foi amigo de Jamil Caram e frequentava as rodas de Choro avareense. Zé Barbeiro, Miltinho multi-instrumentista, Dudáh Lopes, Stanley, Marco Antônio, Nailor Aparecido Azevedo (Proveta), dentre outros tantos, que montaram regionais ou seguiram carreira solo, ajudaram a fundar e alicerçar o Choro paulistano.

\section{Avaré e o choro}

\section{Cidade e cultura}

Avaré, cidade do interior paulista, sendo ela reflexo e parte de um todo, com particularidades e subjetividades próprias. Tal subjetividade, presente na produção cultural, pode ser compreendida como "a noção mais simples de uma superestrutura, que ainda está longe de ser totalmente abandonada, [a noção] [...] de "reflexo", a imitação ou reprodução da realidade da base na superestrutura de uma forma mais ou menos direta" (WILLIAMS, 2011, p. 45). Assim, entendemos ser oportuno traçarmos as origens da sociedade avareense para interpretarmos a disposição de sua rica cultura.

A cidade de Avaré, outrora Rio Novo, foi fundada em 15 de maio de 1862, data que consta em escritura registrada no mesmo ano (PIRES, 1996). O historiador avareense, Gesiel Júnior, entretanto, atenta-nos sobre a demarcação dessa data, "romanceada por uns, questionada por outros, a origem de Avaré continua nublada pela falta de uma versão convincente" (SILVA JR, 2011, p. 18). Seu primeiro e mais importante fundador é o Major Vitoriano de Souza Rocha, o "Audaz Vitoriano", cujo nome pode ser escutado no hino da cidade.

Major da guarda nacional e simpatizante da República, o tropeiro Vitoriano assentou-se no sertão do Rio Novo em meados do século dezenove, antes das leis de terras, atraído pela propaganda de seu parente, o capitão Tito Corrêa de Melo, um dos chefes políticos de Botucatu (SILVA JR, 2012, p. 17). 
Em 1871, "a Lei $\mathrm{n}^{\mathrm{o}} 12$ de março criou a primeira escola pública masculina, sendo nomeado professor o Sr. João Padilha de Queiroz" (PIRES, 1996 p. 22). A cidade cresce junto com as mudanças políticas e sociais do país, tendo visto a guerra do Paraguai, a abolição da escravatura e a Proclamação da República, que causa rebuliços políticos em Rio Novo, que na época contava com uma população de quase dez mil habitantes (SILVA JR, 2012). A base da economia era a agricultura, por conta dos grandes fazendeiros que nela habitavam. Por conta desses aspectos econômicos, a cidade contou com uma grande colônia de imigrantes italianos, que trabalhavam nas fazendas, sua produção era o café, o fumo, a cana, o algodão e os cereais (SILVA JR, 2011), produção que era escoada para o comércio externo.

\begin{abstract}
A República, nas alterações que introduz, marca nitidamente, o extraordinário esforço de adaptação das condições internas às condições externas, de uma capitalização em início a um processo capitalista que atinge a sua etapa imperialista. Com a República, assistimos, realmente, ao apogeu da estrutura colonial de produção: O Brasil é um dos principais supridores de matérias-primas do mercado mundial e o seu produto fundamental é o alimentício que figura em maior volume nas correntes de troca, com a particularidade de fazê-lo ainda sem concorrência (SODRÉ, 1968, p. 294).
\end{abstract}

Com o avanço da cidade, fez-se necessário abrir a primeira agência de correio, em 24 de abril de 1874, com os serviços limitados a três viagens mensais para Botucatu. Em 1875, por meio da Lei ${ }^{\circ} 15$, promulgada no dia 7 de julho, Avaré ganha sua independência administrativa (SILVA JR, 2011), mas é no ano seguinte que tem instaurada a "primeira Câmara Municipal" (PIRES, 1996, p. 27). A então Rio Novo torna-se Avaré, “motivada por razões estritamente políticas, [...] em 1891, no começo da República” (SILVA JR, 2011, p. 35). Sua origem é comemorada em 15 de setembro, mas a data de 7 de julho deve ser lembrada pelos avareenses, pela conquista de sua autonomia político-administrativa (SILVA JR, 2011).

A partir de 1947, Avaré entra em um novo cenário, "as eleições passam ao controle da Justiça Eleitoral, permitindo que a vontade do povo, exercida na urna, fosse respeitada" (SILVA JR, 2011, p. 59). Elemento da democracia e do Estado burguês; contudo, um ganho sem precedentes para o progresso da cidade. Tem como seu primeiro governante, de 1948 a 1951, o advogado Antônio Ferreira Inocêncio (SILVA JR, 2011). Em seu último ano de mandato, Avaré vai escutar pela primeira vez, na Rádio Avaré, o Choro feito na cidade pelo pioneiro Luiz de Paschoal.

Décadas mais tarde, a cidade veria um dos eventos mais significativos para sua cena cultural, a FAMPOP (Feira Avareense de Música Popular), de grande projeção nacional e “caso raro em que os acordes da política e da música deram o tom afinado para a composição de um 
projeto sem precedentes no interior paulista" (SILVA JR, 2011, p. 85). Com a eleição de Paulo Dias Novaes para o cargo de prefeito da cidade, em 1982, a ideia ganha volúpia política; a prefeitura cede espaços e auxilia financeiramente os organizadores para que o festival seja realizado. É em julho de 1983 que o festival acontece no Centro Avareense, transmitido pela Tv Cultura. Estavam presentes em seu júri Zuza Homem de Mello, Walter Negrão, Marcus Baby Durães e Ana Caran (SILVA JR, 2011).

"Era o princípio de uma série de avanços para a MPB fora do eixo Rio-São Paulo" (SILVA JR, 2011, p. 86). A FAMPOP perdura durante anos, estando presentes em solo avareense músicos como Lenine, Chico César, Jorge Vercillo, Moacyr Luz, Milton Nascimento, Rita Ribeiro, Zeca Baleiro, Caetano Veloso, Tim Maia, Gilberto Gil, Paulinho da Viola, Elba Ramalho, Jorge Bem Jor, Ivan Lins, Sá e Guarabira, Fátima Guedes e MPB4, citando apenas alguns dentre os inúmeros artistas homenageados, concorrentes ou vencedores, além dos grandes nomes nos júris tradicionais de cada ano (SILVA JR, 2011).

\section{Felizmente embora o festival tenha desafinado em alguns anos por conta da insensibilidade política de governantes surdos, a memória fonográfica da Fampop está preservada nos discos gravados de 1987 a 1996 e entre 2001 e 2004, pelo menos. Afinal, artistas renomados como Gilberto Gil a até a diva americana Dionne Warwick gravaram canções premiadas em Avaré (SILVA JR, 2011, p. 87).}

A cultura avareense pulula muito antes de seu maravilhoso festival. Em 1882, "as primeiras peças teatrais com registros nos anais de Avaré foram como atração profana em meio a uma das mais tradicionais festas religiosas brasileiras, a do Divino" (SILVA JR, 2011, p. 75). Festa essa que contava com a presença tradicional de chorões, como contará, mais adiante, com a presença de Luiz de Paschoal.

Mas, é para as mulheres que Avaré deve suas mais ricas contribuições culturais. Lembranos Silva Júnior (2011) que a pintora avareense Djanira (1914-1979), com suas "telas e desenhos [...], [que] marcaram essencialmente a arte brasileira do século vinte [...], passou a ocupar espaço merecido em salas de aula da sua cidade natal" (SILVA JR, 2011, p. 81). E outras admiráveis mulheres no campo da ciência, da arte e da política, como Anita Ferreira de Maria, Diva Diniz Corrêa, Martha Fagundes, Laurinda Ramalho de Almeida, Estela Gambini, Nilva Calixto, Lucila Novaes e Bruna Caram, essa última neta de Jamil Caram, "pai” do Choro Avareense (SILVA JR, 2011).

Em 30 de agosto de 1931, Avaré recebe o grande maestro e chorão Villa-Lobos para uma noite de gala para a cultura avareense. "O antigo Cine-Theatro Santa Cruz tornou-se palco de 
um espetáculo memorável: o concerto regido por Heitor Villa-Lobos (1887-1959) " (SILVA JR, 2012, p. 52). Segundo Silva Jr. (2012), o concerto tem início às $20 \mathrm{~h} 30$ em ponto, apresentando "Momoprecoce", fantasia para piano e orquestras, inspirado em um solo de piano; "Carnaval da Criança", incluindo em seu número alguns choros. O maestro estava acompanhado do pianista João de Souza, da cantora Nair Duarte Nunes e de sua esposa, e chegaram a outrora Rio Novo por meio de um projeto cultural, que os possibilitava percorrer as cidades do interior paulista (SILVA JR, 2012). Os convidados "compareceram ao Largo São João, onde a banda municipal, sob a regência de Sebastião Souza Coelho, interpretou números populares" (2012, p. 53).

\section{O embrião do choro avareense}

Filho dos imigrantes italianos Nicola de Paschoal e Ângela Morbio, Luiz de Paschoal foi o embrião do Choro Avareense, nasceu em 4 de novembro de 1913, em Avaré. Sempre fiel à vida citadina, sua relação com a música começou aos onze anos, quando aprendeu a tocar bandolim com Nino Barreira, que mais tarde viria a ser seu cunhado ${ }^{1}$.

Antes de Paschoal começar seus empreendimentos para com a música na cidade, as condições materiais de sua classe determinaram que o futuro bandolinista e cavaquinista de Choro procurasse seu sustento, pois só seria possível se dedicar a música se tivesse o mínimo de condição para fazê-lo. Assim, ele também tomou consciência de seu lugar e pôde seguir. Retomando a discussão que fizemos acima sobre a superestrutura, temos uma prática central e muito importante na formação da mesma, a tomada de consciência de classe; ademais, seja subjetiva e não objetiva, não deve ser descartada como um passo progressivo, como no caso de Luiz de Paschoal. "É evidente que esse processo de formação complica qualquer modelo simples de base e superestrutura [...], a hegemonia do tipo proletária que fosse capaz de desafiar a hegemonia burguesa" (WILLIAMS, 2011, p. 59).

No ano de 1928, Luiz começou a aprender os ofícios de carpinteiro e marceneiro com Plinio Bove, Guerino Stat e Fernando de Moraes. Fez teste para entrar na oficina de Moraes, foi aprovado e contratado para ganhar duzentos mil réis por mês, o descendente de italianos

\footnotetext{
${ }^{1}$ Esses depoimentos foram coletados pelo autor do artigo por meio de entrevistas realizadas com chorões e personagens citadinos: FERNANDO CARAM (concedida em 09/08/2019, por via remota); ALTINO TOLEDO (concedida em 22/04/2020 e 23/04/2020, por via remota); FRANCISCO PIRES CAMARGO (concedida em 23/04/2020, 24/04/2020 e 01/05/2020, por via remota); e ESCRITOS PESSOAIS DE LUIZ DE PASCHOAL, datilografado por seu filho, Geraldo de Paschoal em 1995. Utilizaremos alguns trechos das entrevistas ao longo deste artigo.
} 
advindo das classes populares nunca havia faturado tanto, até então ganhava apenas dez $^{2}$. A historiadora avareense Flora Bocci traz um interessante relato sobre os andamentos da música avareense no ano de 1928, destaca, em uma nota do jornal O comércio de Avaré, que "continua prendendo a atenção pública o magnífico Bairro do Braz, onde aos domingos e feriados costuma tocar uma banda de música [...]. O sr. Caldeira Braz vae construir um bello coreto para a música" (BOCCI, 2008, p. 134).

O ano de 1932 é marcado pelo Concerto de Piano Clássico em benefício das obras da Igreja Matriz, com repertório de Chopin a Beethoven, o jornal avareense $O$ Commércio destaca as musicistas que fizeram parte do espetáculo: "o concerto de piano das talentosas conterrâneas senhorinhas Esther Novaes, Diva Cruz e Martha Fagundes, distintas alunas da senhora Hilda Rodrigues Miller" (BOCCI, 2008 p.156). É em 9 de julho desse mesmo ano, na festa do divino, que Luiz de Paschoal começou a tocar no "Conjunto do Santino", na mesma noite em que conheceu sua esposa, Amélia Quartucci. Quando o relógio apontava oito horas da noite, foram surpresos com a notícia dos acontecimentos que deflagraram a revolução constituinte ${ }^{3}$.

É por conta desse acontecimento que surge o causo mais curioso na história do Choro Avareense. Em entrevista, Francisco Camargo Pires, genro de Luiz de Paschoal, conta que houve, em terras avareenses, um encontro entre Luiz e Pixinguinha. Segundo Pires, Paschoal "conheceu Pixinguinha quando as tropas da revolução passaram por Avaré, estava tocando, quando chegou e conversou com ele, notou o rosto dele cheio de marcas". A veracidade do fato se explica exatamente pelas "marcas no rosto", Pixinguinha realmente tinha essas marcas, varizes, causas de uma doença na infância, que o levou ao apelido de Bexinguinha (pareciam marcas de bexigas), e depois, Pixinguinha. ${ }^{4}$

Em 1941, sua relação com a música começou a se acentuar. Fundou o conjunto "Maestro Pontes", juntamente com Álvaro Filgueiras, Benedito Tunucchi, Antônio Prestes, Urbano Rodrigues, Palmito Bonugli, Santino de Paschoal, Astrogildo Pontes, Vircilino Mariano, Manuel Barreira, Osvaldo Paulino, Tarciso Godinho e Aristide Rodrigues. ${ }^{5}$

Luiz de Paschoal, marceneiro de profissão e músico por paixão, filho de trabalhadores italianos, preocupava-se com as condições de vida dos trabalhadores avareenses. Em 30 de maio de 1948, fez parte do grupo que, sob a liderança de Padre Emilio Immos, fundou o Círculo

\footnotetext{
${ }^{2}$ Cf. nota 1 .

${ }^{3}$ Cf. nota 1 .

${ }^{4}$ Cf. nota 1 .

${ }^{5} \mathrm{Cf}$. nota 1 .
} 
Operário de Avaré. Já em 1950, eleito presidente dessa entidade, instituiu a "Corrida do Operário", que até hoje acontece no $1^{\circ}$ de maio; ademais, em outubro daquele ano foi eleito vereador à Câmara Municipal. ${ }^{6}$

Em 1951, o chorão inicia sua contribuição aos andamentos do Choro Avareense, ano em que identificamos a origem do Choro na cidade. Foi em uma reunião com outros músicos citadinos que o conjunto "Seresteiros de Outrora" foi fundado. O Choro, como também o samba e as valsas, começaram a granjear o popular avareense. Isso se deve ao fato desse conjunto se apresentar durante anos na Rádio Avaré. ${ }^{7}$ Os Seresteiros tinham em sua formação o Maestro Sebastião Fonseca (Flauta), José Domingo, o Zé Lumião (violão e voz), Santino de Paschoal (clarinete), Orlando Cassetari (violino), Luiz de Paschoal (cavaquinho), Nino Cassetari (violino), Plinio Bove (violão) e Tico Bove (voz). ${ }^{8}$

Três anos depois, Paschoal foi eleito tesoureiro do São Paulo F.C (Avaré), tendo permanecido no cargo durante sete anos. Juntamente com o Círculo Operário e o Padre Emilio Immos, participou da construção da sede paroquial, na Praça Tavares. No ano de 1968, foi empossado presidente da Associação Comercial e Industrial de Avaré, e também do Lar São Vicente. No mesmo ano, foi campeão de bocha dos jogos regionais da sorocabana, e considerado por todos o líder bochófilo da região. ${ }^{9}$

Com a vida entrelaçada aos caminhos públicos, é em 1969 que ele funda, com seu sobrinho Guerino, o conjunto "Jovem Guarda". Nesse mesmo ano, surge a sua maior contribuição para o Choro de caráter popular em Avaré, o chorão organizou um outro conjunto, cuja influência reverbera até os dias de hoje nas rodas de Choro Avareense, o conjunto "Tio Luiz" - é assim que Luiz de Paschoal é conhecido em meio aos chorões citadinos. O grupo tinha a seguinte formação: "Tio Luiz" (regência, cavaquinho e bandolim), Orestes Fagnani, Totó da Prefeitura, Sansão do Violão e Armandinho do Acordeom. ${ }^{10}$

Nos anos de 1970, Luiz participou da fundação do Clube Avareense de Música e Teatro, além de ter sido diretor da Cooperativa de Consumo de Avaré e da Associação Ferroviária Avareense. $\mathrm{Na}$ década seguinte, nas comemorações do aniversário da cidade, em 15 de setembro de 1981, organizou um conjunto com seu irmão Paulo, Sansão, Armando,

\footnotetext{
${ }^{6}$ Cf. nota 1.

${ }^{7}$ Cf. nota 1 .

${ }^{8}$ Cf. nota 1 .

${ }^{9}$ Cf. nota 1 .

${ }^{10} \mathrm{Cf}$. nota 1 .
} 
Armandinho e Timochenco, que tocava nas paradas do desfile enquanto vinte casais de jovens dançavam. ${ }^{11}$

Participou da edificação da Igreja São Benedito e das reformas do Lar São Vicente, bem como da construção da sede do Circuito Operário, no largo Santa Cruz. Foi responsável pelas canchas de bocha do Lar São Vicente, e dedicou a maior parte de seu tempo aos assistidos da entidade, onde também sempre estavam presentes as rodas de Choro do "Tio Luiz". ${ }^{12}$ Aos oitenta anos, recebeu uma expressiva homenagem de seus filhos na Rádio Avaré, em sessão promovida por Elias Ward e Marilia Pires. Palmeirense fanático, Seu Luiz de Paschoal faleceu em 24 de abril de 1998, ano em que seu time foi campeão da Copa do Brasil pela primeira vez, uma grande perda para a cidade e para a música. ${ }^{13}$ "Luiz de Paschoal é um avareense que dedicou toda a sua vida aos seus conterrâneos, entre outros, nos campos da música, dos esportes, da religião e principalmente da assistência social". ${ }^{14}$

\section{Choro avareense levado a sério}

\section{O pai do choro}

Em 1975, surge em Avaré aquele que viria a ser o "pai” do Choro na cidade, Jamil José Ribeiro Caram, chorão autodidata, tocava violão, cavaquinho e bandolim. Com sua família, veio de Presidente Prudente para Avaré como gerente de uma grande algodoeira, quando a empresa beneficiadora de algodão fechara sua filial em Presidente Bernardes, cidade na qual trabalhava, relata seu filho Fernando Caram. ${ }^{15}$ A questão econômica também se manifesta e está sempre presente nas produções culturais, isso não é diferente na cidade de Avaré, que avançava industrialmente e desenvolvia suas forças produtivas, tais condições materiais trouxeram o mestre Jamil Caram aos ares avareenses.

Já em Avaré, Jamil soube de um sargento da polícia que tocava violão seis cordas, música clássica, sargento que atendia pelo nome de Antônio Teixeira de Abreu, futuro pilar da cultura “chorística' em Avaré. O Choro feito profissionalmente na cidade é resultado do entrelace dessas duas personagens.

\footnotetext{
${ }^{11}$ Cf. nota 1.

${ }^{12} \mathrm{Cf}$. nota 1.

${ }^{13}$ Cf. nota 1.

${ }^{14} \mathrm{Cf}$. nota 1.

${ }^{15} \mathrm{Cf}$. nota 1 .
} 
Jamil Caram era um exímio musicista, mas não tinha didática para lecionar, para ele, quem tocasse Choro havia de ter um bom ritmo, tocar de ouvido. ${ }^{16}$ Isso não significava que não era rígido em suas rodas, como dizia Teixeira sobre o amigo: "Ele era muito rigoroso. Se a gente fazia coisa errada ele falava: ‘Tá errado! Não é isso!’” (TEIXEIRA NETO, 2014, p. 128).

Teixeira, em entrevista concedida a Eduardo Teixeira Neto, em 2014, diz que o amigo Jamil era aventureiro, impulsivo e muito focado, e que juntos rodaram cidades tocando Choro, dentre elas Presidente Prudente, Arujá, Lins, Botucatu e até Rio de Janeiro. Cita ainda uma conversa entre os dois acerca das aventuras que tinham juntos: "Eu perguntei onde iríamos tocar e ele respondeu: Em Prudente! Mas Jamil, são 300 km daqui! e ele respondeu: 'Mas você não está fazendo nada!' E ficamos três dias em Presidente Prudente" (TEIXEIRA NETO, 2014, p. 129).

O gerente da algodoeira gostava mesmo era de tocar, apaixonado por Choro, comprou um bar em Avaré para concretizar sua vontade de juntar o Choro e a noite, o bar "Roda Viva". Ali pôde realizar sua vontade, rodeado de seus companheiros músicos, pois, como diz Altino Toledo em entrevista acerca da vida noturna avareense: "ninguém gostava muito que ficasse tocando nesses lugares, e ele (Jamil) gostava de tocar no bar". ${ }^{17}$

Caram não possuía um grupo formado, não fazia apresentações públicas. Como diz Toledo: "ele só tocava em roda... convidava as pessoas para ir a casa dele, sempre muita comida, bebida, era aquela coisa, comida, bebida e tocar choro". ${ }^{18}$ A boemia sempre foi característica das rodas de Choro, desde os originários chorões mestiços, operários das primeiras fábricas no Rio de Janeiro no século XIX, que cunharam o dito "o gato está dormindo no fogão", para designar a fartura que os esperava. Era praticamente essencial as comidas e bebidas para que houvesse as rodas (DINIZ, 2013).

Entretanto, no ano de 1988, Jamil forma um Regional de última hora para um programa da TV Cultura. Intitulado "Avaré faz o Show”, o conjunto era composto por Jamil Caram no Bandolim, Altino Toledo no pandeiro, Teixeira de Abreu no violão sete cordas, Nilson Calamita no violão seis cordas e Fernando Caram no cavaco. O grupo foi chamado de "Regional Jamil Caram" e se apresentou na Concha Acústica, na Praça Central de Avaré. A televisão, depois do rádio, também foi objeto de poder econômico, encontravam-se ali abusos publicitários, que

\footnotetext{
${ }^{16}$ Cf. nota 1.

${ }^{17}$ Cf. nota 1.

${ }^{18} \mathrm{Cf}$. nota 1.
} 
quase sempre tamponavam as demandas culturais da população. O Regional Jamil Caram foi necessário e resistente a essa problemática, levando, assim, a cultura popular interiorana para a televisão brasileira. "A televisão operou, assim, com o seu enorme poder financeiro, no sentido de deformar artes que passaram à comercialização maciça, destruindo-lhes as velhas estruturas e privilegiando alguns de seus elementos" (SODRÉ, 1986, p. 100).

Os empreendimentos do Regional deram grande popularidade para o Choro na cidade, formando inúmeros chorões e adeptos ao gênero, podemos, pois, considerar o Regional de Jamil como o estopim da profissionalização e divulgação do Choro em Avaré (TEIXEIRA NETO, 2014). Ademais, nos anos de 1970, junto ao governo do Estado de São Paulo, Jamil ajudou a criar um projeto de divulgação da música popular brasileira, em um caminhão, que às vezes servia de palco e levava músicos para se apresentarem em praças pelo interior aos finais de semana. Caram se manteve em terras avareenses até a década de 1990, quando se mudou para a capital. Em São Paulo, participava, aos sábados, das tradicionais rodas de Choro proporcionadas pela loja “Contemporânea Instrumentos Musicais”, onde levara, há alguns anos atrás, o então jovem violonista Yamandu Costa, hoje grato a Jamil por ter lhe apresentado diversos músicos (FOLHA DE SÃO PAULO, 2014).

É com essa genial simplicidade de um verdadeiro chorão que Jamil Caram ficou conhecido entre os grandes músicos, e, assim, colocou Avaré na rota do Choro paulista e nacional. Inúmeros chorões de grande calibre vinham respirar os ares avareenses nas rodas organizadas por ele, a exemplo de Altamiro Carrilho, Luizinho 7 cordas, Faninho da Flauta, Izaías do Bandolim, Evandro do Bandolim, Garcia e outros tantos. ${ }^{19}$

\section{Se você vai pra São Paulo com aqueles caras profissionais e fala do Jamil, todo mundo conhece. Todo profissional das antigas conhece o Jamil. É como o Evandro dizia: Ir a Avaré e não visitar o Jamil é o mesmo que ir a Roma e não visitar o papa (TEIXEIRA NETO, 2014, p. 125).}

Por essas e outras podemos então afirmar que Jamil Caram foi o "pai" do Choro em Avaré, o elo de ligação das antigas rodas do "Tio Luiz" até as novas gerações, responsável pela divulgação, propagação e evolução do Choro Avareense. Nas palavras de Toledo: "Jamil deu um impulso enorme para o Choro no município, devido as rodas que organizava... dando oportunidade para as pessoas aprenderem também, não fica só um grupo fechado e ninguém toca, ninguém pode entrar". ${ }^{20}$ Teixeira também comenta sobre a importância do amigo: "Eu

\footnotetext{
${ }^{19}$ Cf. nota 1.

${ }^{20}$ Cf. nota 1 .
} 
considero (Jamil) o pai do Choro em Avaré, pois foi com ele que o Choro ganhou reconhecimento... abriu meus olhos e me fez tocar Choro" (TEIXEIRA NETO, 2014, p. 129).

Em 21 de julho de 2014, o Choro avareense perdeu Jamil Caram, mas seu legado continua em sua família, a neta Bruna Caram é cantora profissional, bem como as filhas Ana e Valéria (A FOLHA DE SÃO PAULO, 2014).

\title{
O Sete Cordas
}

Filho de Francisco Teixeira de Abreu e Dorvalice Freitas de Abreu, o mestre sete cordas e pilar fundamental para o Choro Avareense, Antônio Teixeira de Abreu, o popular Teixeira, nasceu em São Paulo, em 1944, e teve seu primeiro contato com a música através da mãe, também violonista (EMNCENA FILMES, 2018). Veio para o interior paulista aos oitos anos de idade, e residiu em Lorena até os vinte e dois, quando voltou para casa do pai na capital. Ingressou na Polícia Militar em 1965, durante a Ditadura Civil-Militar.

A noção geral de totalidade tende a entender a ideologia como simples dominação; contudo, a ideologia dominante, reforçada pela ditadura reacionária no Brasil, a partir do ano de 1964, que angariou jovens soldados como Teixeira de Abreu para as suas fileiras - tal como acontecia com os músicos civis do século XIX, na época de Anacleto de Medeiros, que se alistavam ao exército para ter uma melhora nas condições de vida - na verdade, apresenta as diferentes formas que a dominação pode tomar concretamente.

\begin{abstract}
Pois se ideologia for apenas um conjunto abstrato e imposto de noções, se as nossas ideias, pressupostos e hábitos sociais, políticos e culturais forem meramente o resultado de uma manipulação específica, de um tipo de formação aberta que pode ser simplesmente encerrado ou removido, então seria muito fácil mover ou alterar a sociedade do que na pratica sempre o foi ou é. Essa noção de hegemonia, que satura profundamente a consciência de uma sociedade, parece ser fundamental para mim. E ao contrário das noções gerais de totalidade, a hegemonia possui a vantagem de enfatizar, ao mesmo tempo, a realidade da dominação (WILLIAMS, 2011, p. 52).
\end{abstract}

A história de Teixeira em Avaré começa quando ele é cotado para fundar uma Rádio Patrulha na cidade, a intenção era ficar quinze dias, mas acabou sendo uma vida. Chegando à cidade interiorana, vai morar em uma pensão chamada "Puxa Faca", na Rua Minas Gerais. Ao caminhar até a casa de um amigo, escuta o som de um violão, era Lazaro de Mello, o "Lazinho", que se apaixona pela maneira como Teixeira manuseia seu violão e acaba por ser o primeiro aluno do sargento (EMNCENA FILMES, 2018). 
Teixeira não teve seu primeiro contato com a música profissional através do Choro, era violonista clássico, mas abandonara a carreira por conta da vida solitária. Como diz em entrevista para Teixeira Neto, em 2014: "Eu tinha chegado a tocar em auditório, fazer concerto, mas violão clássico é aquele negócio, né? Você é sozinho, estuda sozinho, vai pro teatro sozinho, toca sozinho, sai de lá e vai pros bastidores sozinho e vai embora sozinho e aquilo me cansou" (TEIXEIRA NETO, 2014, p. 125).

Sua história com o Choro está ligada diretamente a Jamil Caram, como ele próprio aponta: "Foi através dele (Jamil) que eu (Teixeira), um violonista clássico, fui conhecer o Choro [...]" (TEIXEIRA NETO,2014 p. 125). Teixeira, contudo, também reconhece Luiz de Paschoal como o precursor do Choro Avareense, nessa mesma entrevista, diz: “Antes do Jamil tinha o conjunto do Tio Luiz que tomava conta do asilo dos velhos [...] Lar São Nicolau" (TEIXEIRA NETO, 2014, p. 125).

Conheceu Jamil através de um amigo em comum, Carlos Beltrami, funcionário do Banco do Brasil, e assim começa sua ligação com o Choro. "Eu (Teixeira) fui a casa dele (Jamil), sem violão sem nada, Jamil pegou o bandolim, colocou um violão na minha mão e disse: 'Acompanha ai!' [...] E ele falou 'Você precisa vir tocar comigo!'.” (TEIXEIRA NETO, 2014, p. 126). Nessa ocasião, Teixeira conhece o violão sete cordas: "Eu volto a tocar, mas quero tocar esse violão aí. Eu não conhecia o violão sete cordas" (TEIXEIRA NETO, 2014, p. 126).

Então, apaixona-se pelo gênero musical e começa seus empreendimentos para com o Choro. Forma, com Jamil Caram, o primeiro conjunto propriamente de chorões, composto pelos amigos, como diz Teixeira: "O Armando [...] começou a tocar cavaquinho. O sobrinho dele (Jamil) que tocava pandeiro [...], Fábio o nome dele. Ana Lúcia tocava flauta. Ele me apresentou o João Cassetari, que tocava clarinete" (TEIXEIRA NETO, 2014, p. 127). A ideia de se tornar professor de música nasce a partir desse momento, diz o chorão: “As pessoas me viam tocar e perguntavam se eu não queria ensiná-los [...] comecei ensinando um, depois outro. E montamos um grupo aqui, tudo de ouvido" (TEIXEIRA NETO, 2014, p. 127).

Já nos anos de 1980, Teixeira irá conhecer o futuro bandolinista profissional, amigo e professor do conservatório de Tatuí/SP, Altino Toledo. Sobre ele, diz Teixeira: “[...] não lembro quem me falou que tinha alguém na cidade que tocava bandolim e eu quis conhecer pois só conhecia o Jamil” (TEIXEIRA NETO, 2014, p. 127). Os dois, no início, tocaram juntos a música "André de sapato novo", mas já havia Rosana também (filha de Teixeira), que tocava maravilhosamente bem bandolim, portanto, Toledo ficou no violão seis cordas. Relata-nos 
Teixeira: "O Altino vinha todo domingo às $8 \mathrm{~h}$ da manhã, me tirava da cama pra gente tocar" (TEIXEIRA NETO, 2014, p. 128).

A partir disso, forma-se um regional aos moldes do sargento, segundo Toledo, era bem organizado "com repertório na mão, as frases todas estudadas, ele gostava disso [...] já era daquela classe ligada no Jacob do Bandolim, não tinha bagunça". ${ }^{21}$ Esse regional chegou a fazer apresentações em teatros e festivais. Conta-nos Toledo: "Nós fizemos apresentações em teatro [...] sobre a história da música popular brasileira [...] a gente tocava coisas da Chiquinha Gonzaga”. Esse grupo era formado pelas duas filhas de Teixeira, Rose e Rosana, Maurício Zeni no cavaquinho, Altino Toledo no violão seis cordas, Cezinha (barbeiro) no cavaquinho e Teixeira no violão sete cordas, grupo que chegou a ser convidado para tocar em festivais no Rio de Janeiro. ${ }^{22}$ Rosana era um fenômeno, bandolinista da maior estirpe, de identidade musical invejável, acabou falecendo, mas não sem antes deixar todos que a conheciam caírem em lágrimas ao vê-la tocar seu bandolim. Como em um belo dia que Teixeira convida Jamil para escutar o bandolim de Rosana: "Jamil veio aqui [...], tocamos "Doce de Coco". Foi outra choradeira" (TEIXEIRA NETO, 2014, p. 127).

Com o tempo, esse conjunto foi se dissipando, ficaram apenas Toledo e Teixeira, que ensaiaram por dois ou três anos, depois passaram a convidar outras pessoas, como conta Toledo: “o Serginho Fragoso [...], Césinha cabeleireiro [...] tocava cavaquinho, o Toti que é contrabaixista [...], Nilton Baiano, [...] dessas rodas do Tio Luiz, Seu Orestes Fagnani [...], o Flávio Calamita [...], mas não tinha um grupo certo".23

Seus feitos como professor e chorão avareense começaram a granjear enormes frutos para o gênero em escala nacional. Seu aluno, João Camarero, hoje ocupa a cadeira de Dino sete cordas no conjunto "Época de Ouro", criado por Jacob do Bandolim. Luthier e fã incondicional de Dino, recebeu de seu ex-aluno um grande presente, o violão sete cordas de Dino, com a missão de concertar suas antigas mazelas. Teixeira, que nunca havia encontrado um violão de que gostasse inteiramente, escaneia o violão inteiro e passa a confeccionar no mesmo molde (EMNCENA FILMES, 2018).

Suas façanhas para com a cidade o fizeram ganhar o título de Cidadão Avareense, o honorário foi votado na câmara dos vereadores em 2004. Ganhou também um documentário

\footnotetext{
${ }^{21}$ Cf. nota 1.

${ }^{22}$ Cf. nota 1.

${ }^{23}$ Cf. nota 1.
} 
intitulado "Mestre Teixeira - O homem e o choro", de autoria de Amauri Albuquerque, do grupo Emncena Filmes ${ }^{24}$ - material que utilizamos neste trabalho -; entre outras homenagens feitas pela Secretaria Municipal de Cultura, como um pôster seu com uma pequena biografia, colocado em uma sala do Projeto Guri, onde foi também professor, no Centro Cultural "Esther Pires Novaes" (FORA DE PAUTA, 2019).

Faleceu em 17 de abril de 2019, aos 74 anos. Mestre Teixeira foi um chorão de magnitude nacional, reverberará sua influência na música para sempre. Camarero, considera-se discípulo de Teixeira, assim como Toledo. As raízes que criou no Choro se espalharam e não pararam de ganhar vida, seu legado é concreto, sua vida dedicada à música fez crescer e solidificar o Choro Avareense, até chegar a sua realização mais concreta, o Clube do Choro de Avaré.

\section{Clube do Choro}

O Clube do Choro é a realização material das façanhas feitas pelos primeiros chorões na cidade, um de seus fundadores é Altino Toledo, professor no conservatório de Tatuí e disseminador do Choro Avareense. É em 1980 que Toledo começa seus caminhos no gênero: “conheci um cara que tocava com o Teixeira, apareci lá [...] para ver se aprendia aquilo que eles estavam tocando, logo de cara já comecei a tocar no grupo $[\ldots] .{ }^{25}$

Toledo começa a participar das rodas feitas por Jamil Caram e entra no circuito dos chorões avareenses: “[...] comecei a tocar aqui, estudar com o Teixeira, a participar das rodas na casa do Jamil. O Tio Luiz ainda tocava um pouquinho algumas coisas, mas o pessoal já estava bem mais de idade [...]. ${ }^{26}$

Foi percursor do curso de Choro no Conservatório de Tatuí. Até sua chegada na cidade, em 1991, não havia nenhuma matéria pedagógica direcionada ao gênero: “[...] chegando lá, logo no outro ano montei um grupo chamado 'Quebrando o Galho' com um amigo, o Alexandre Bauab [...], depois de sete anos eles convidaram a gente para montar o curso de Choro". ${ }^{27}$

O conservatório de Tatuí é a primeira escola de música brasileira, mantida por um Governo Estadual, a incluir em seu currículo o gênero "Choro" como matéria pedagógica. O curso é oferecido desde o ano de 1999. Nenhuma outra escola do Brasil, estadual ou particular - com exceção da escola de Choro de Brasília, mantida pelo Governo Federal e fundada um ano antes, em 1998, teve a iniciativa

\footnotetext{
${ }^{24} \mathrm{O}$ link de acesso ao documentário está disponível nas referências deste artigo.

${ }^{25} \mathrm{Cf}$. nota 1.

${ }^{26} \mathrm{Cf}$. nota 1 .

${ }^{27}$ Cf. nota 1 .
} 
de abrir espaço a esse tão importante gênero da música brasileira (BAUAB JR, 2009, s/p).

Toledo é a continuação dos empreendimentos de Jamil e Teixeira para com o Choro. Os chorões avareenses, em sua maioria de classe média, tinham como lazer o gênero, não necessitavam de capital advindo da música. Toledo foi o primeiro a se profissionalizar como músico tornando-se professor, levantando seu sustento através do Choro, conforme afirma em entrevista: "acho que sou o primeiro (entre os chorões avareenses) a ter o sustento trabalhando com o Choro [...] depois veio meu filho (Rafael Toledo), também o João Camarero". ${ }^{28}$

Ademais, é em 1990 que a ideia de um Clube do Choro começa a pairar no meio avareense, mas Toledo, em entrevista para Teixeira Neto, em 2014, atenta sobre um ponto: somente em "1997, elaboramos um estatuto e fizemos a primeira reunião de fundação". (TEIXEIRA NETO, 2014, p. 123). É a partir dessa data que entendemos o embrião do Clube do Choro de Avaré. Fato é que a "parte burocrática (do Clube do Choro de Avaré), ficou sem finalização até 2012, quando finalmente fizemos os registros necessários para a legalização do clube" (TEIXEIRA NETO, 2014, p. 123). Para não ultrapassarmos o objetivo deste artigo, não entraremos mais a fundo em suas realizações, mas é válido comtemplar a principal proeza do Clube, o Festival de Choro de Avaré. De reconhecimento nacional, trouxe inúmeros grandes chorões e regionais para a cidade, como o bandolinista Déo Rian. Por fim, é necessário ressaltar que não consta mais registros da existência do Clube na cidade, tendo sido encerrado seu CNPJ em janeiro de 2020.

\section{Considerações finais}

Ao fazermos uma incursão nos estudos culturais, observamos que a base econômica exerce pressão na superestrutura, mas quando falamos especificamente em uma gama de pessoas num lugar determinado, no nosso caso, Avaré/SP, é mais “complexo e mais contraditório do que o desenvolvimento metafórico da noção de 'base' poderia permitir que percebêssemos" (WILLIAMS, 2011, p. 47). A cultura é sempre de uma determinada sociedade e a produção cultural é uma fábrica de subjetividade, pois ela materializa valores na medida em que está inserida em um processo produtivo. São ideias em forma; por isso, não se pode compreender um processo artístico e cultural sem entender também o seu processo de formação.

\footnotetext{
${ }^{28} \mathrm{Cf}$. nota 1.
} 
Percebemos que os chorões que exerciam outras profissões tinham no Choro um lazer. Em sua maioria, na contemporaneidade, são pertencentes a pequena burguesia; contudo, como diz Toledo em entrevista: "a gente vê que é a mesma coisa, porque os músicos profissionais da cidade, por exemplo, não tocam Choro, são sempre amadores que tem outra profissão". Exemplificando, os chorões do "século XIX e do início do presente século (XX) eram, na sua quase totalidade, representantes da baixa classe média do Segundo Império e da Primeira República" (TINHORÃO, 1997 p. 117). Como vimos, em Avaré, Jamil Caram foi gerente de uma grande empresa algodoeira, ao trazer músicos importantes para a cidade, levantou-se uma questão, como isso se dava? Segundo Toledo: "eram contratados [...], foi o caso do Izaías (do bandolim), como eles tinham um pouco de "grana" contratavam os caras para vir. Nunca conversei formalmente com ninguém sobre isso, mas a gente percebia que os caras eram tipo contratados (alguns)". Os chorões do ciclo avareense são médicos, fazendeiros, funcionários de bancos etc., continua Toledo: "essa classe média é a que sempre esteve no Choro desde o começo, né?". 29

Depois de percorrermos a formação do Choro em Avaré, podemos dimensionar a importância e grande colaboração desses chorões para com a evolução da cultura "chorística". O que seria do Choro Avareense sem a figura ilustre de Luiz de Paschoal, sem as sete cordas vibrantes do mestre Antônio Teixeira de Abreu? Jamil Caram, querido, reverenciado e lembrado por todos que já tiveram algum contato com o Choro. Esse ilustre chorão ajudou a inserir o grande violonista Yamandu Costa nas fileiras da música brasileira. Na geração seguinte do Choro avareense, Altino Toledo criou um enorme espaço para o Choro no Conservatório de Tatuí. Não podemos deixar de mencionar Alexandre Bauab Jr., que, ao lado de Toledo, implantou, com pioneirismo no estado de São Paulo, o gênero "Choro" no currículo de uma escola de música (o Conservatório de Tatuí); antes deles, somente existia a escola de Choro de Brasília, mantida pelo governo federal. Não podemos esquecer da última geração, representada por Rafael Toledo, excelente percussionista e renomado nacionalmente, e João Camarero, discípulo de Teixeira e grande violonista, hoje no "Época de Ouro". O Clube do Choro de Avaré e o Festival de Choro de Avaré, angariaram inúmeros chorões e futuros chorões para a cultura "chorística". Músicos que cortejaram e ainda cortejam uma boa e velha roda de Choro estão pelas ruas da cidade, que vive, respira e dissemina a primeira música popular brasileira urbana, o Choro.

\footnotetext{
${ }^{29}$ Cf. nota 1.
} 


\section{Referências}

AMARAL JR, José de Almeida. Garoto: uma breve história virtuosa. Revista do Choro. São Paulo, 4 de jun. 2015. Disponível em: https://revistadochoro.com/artigos/garoto-uma-breve-historiavirtuosa/. Acesso em: 20 de jun. de 2020.

BAUAB JR., Alexandre. 23 de abril: Dia Nacional do Choro. Ensaio Magazine. Tatuí-SP. Ano IV. n. 48. p. 03, 2009.

BOCCI, Flora M. B. Uma Divertida Máquina do Tempo em Avaré. Taquarituba: Editora Gril, 2008.

CAZES, Henrique. Choro do quintal ao municipal. 4. ed. São Paulo: Editora 34, 2010.

DINIZ, André. Almanaque do choro: a história do chorinho, o que ouvir, o que ler, onde curtir. Rio de Janeiro: Zahar, 2003.

FORA DE PAUTA. Avaré se despede do violonista Teixeira, mestre do Choro. 18 de abr. 2019, Avaré. Disponível em: https://foradepauta.com/avare-se-despede-do-violonista-teixeira-mestre-do-choro/. Acesso em: 20 de jun. 2020.

HOBSBAWM, Eric J. Sobre História. São Paulo: Companhia das Letras, 2013.

MESTRE TEIXEIRA: O Homem e o Choro. Direção: Amauri Albuquerque. Produção de Amauri Albuquerque. Avaré: Emncena Filmes, 2018. (61 min.). Disponível em: https://www.youtube.com/watch?v=gdf9m2IVk-Y; https://vimeo.com/emncenafilmes. Acesso em: 20 de jun. 2020.

NASSIF, Luís. O Gênio de Garoto do banjo. Folha de São Paulo. São Paulo, 28 de mar. 1999. Disponível em: https://www1.folha.uol.com.br/fsp/dinheiro/fi28039907.htm. Acesso em: 20 de jun. de 2020.

ORRU, Caio V.Z. Entrevista com Altino Toledo realizada em 22/04/2020 e 23/04/2020. Avaré. Registro Oral. Via Remota.

ORRU, Caio V.Z. Entrevista com Fernando Caram realizada em 09/08/2019. Avaré. Registro Oral. Via Remota.

ORRU, Caio V.Z. Entrevista com Francisco Pires Camargo realizada em 23/04/2020, 24/04/2020 e 01/05/2020. Avaré. Registro Oral. Via Remota.

PINTO, Alexandre Gonçalves. O choro: reminiscências dos chorões antigos. 3. ed. Rio de Janeiro: Acari Records, 2014.

PIRES, Jango B. A. Um pouco da história do Avaré "Outrora Rio Novo”. 2. ed. São Paulo: Arcádia, 1996.

SEVERIANO, Jairo. Uma história da música popular brasileira: das origens à modernidade. 4. ed. São Paulo: Editora 34, 2017.

SILVA JR, Gesiel T. Avaré em memória viva II. Taquarituba: Ed. Gril, 2011.

SILVA JR, Gesiel T. Avaré em memória viva III. Taquarituba: Ed. Gril, 2012.

SODRÉ, Nelson Werneck. Formação Histórica do Brasil. 5. ed. São Paulo: Ed. Brasiliense, 1968. 
SODRÉ, Nelson Werneck. Síntese de História da Cultura Brasileira. São Paulo: Ed. Difel, 1986.

TAFFAREL, A. Jamil J. R. Caram (1926-2014) - Tocou choro e incentivou artistas. Folha de São Paulo, 24 de jul. 2014. Disponível em: https://www1.folha.uol.com.br/paywall/login.shtml?https://www1.folha.uol.com.br/cotidiano/2014/07/ 1490386-jamil-jose-ribeiro-caram-1926-2014---tocou-choro-e-incentivou-artistas.shtml. Acesso em: 20 de jun. 2020.

TEIXEIRA NETO, E. Clube do choro Jamil Caram. Trabalho de Conclusão de Curso (Graduação em Arquitetura e Urbanismo) - Universidade do Sagrado Coração, Bauru/SP, 2014.

TINHORÃO, José R. Música Popular: um tema em debate. 3. ed. São Paulo: Editora 34, 1997.

TINHORÃO, José R. História Social da Música Popular Brasileira. 2. ed. São Paulo: Editora 34, 2010. VASCONCELOS, Ary. Carinho Etc.: História e Inventário do Choro. Rio de Janeiro: Gráfica editora do livro, 1984.

VASCONCELOS, A. Raizes da Música Popular Brasileira. Rio de Janeiro: Editora Rio Fundo, 1991.

WILLIAMS, Raymond. Marxismo e Literatura. Rio de Janeiro: Zahar, 1979.

WILLIAMS, Raymond. Cultura e Materialismo. São Paulo: Ed. Unesp, 2011. 
Revista Música, v. 21 n. 1 - Dossiê Música em Quarentena (parte II); Dossiê Encontro Internacional de Teoria e Análise Musical - 10 Anos Universidade de São Paulo, julho de 2021

ISSN 2238-7625 